\title{
DYNAMIC AND STATIC TESTS OF TENDONS FOR XENOGENEIC APPLICATIONS
}

\author{
K. Joszko*, B. Gzik-Zroska**, M. Gzik ${ }^{* * *}$, E. Kawlewska ${ }^{\dagger}$, M. Burkacki ${ }^{*}$, S. Suchoń ${ }^{\text {t⿱ }}$
}

\begin{abstract}
In this paper it was presented the results of experimental tests of swine tendons for xenogeneic applications. It was performed the static tensile tests and the low-cycle fatigue tests. Obtained results enabled to predict the optimal swine tendon that could be applied in reconstructive surgery. It was stated that the anterior tendon of digiti III and IV retains the best viscoelastic properties, that is particularly important due to the fatigue nature of interactions in this material during human movement.
\end{abstract}

Keywords: static tensile test, fatigue tests, swine tendon, dynamic modulus of elasticity

\section{Introduction}

Nowadays the more and more popular are the xenogeneicgrafts. Due to the difficulties connected with obtaining the transgenic specimens, it is necessary to replace them with the zoonotic samples. Therefore it is inevitable to expand our knowledge about these kinds of biomaterials (Kemper et al., 2017, Perz et al., 2015, Szarek et al., 2012). Tendons due to their structure and functions often get injured and require reconstruction. In tissue engineering and regenerative medicine there are used the xenogeneic materials materials obtaining from another species. Due to the similar anatomical structure, porcine tissues are used to replace the human tissue (Kajzer et al., 2013, Pezowicz et al., 2012). Therefore it is important to perform the biomechanical investigations to obtain the properties of zoonotic structures and compare them with human's properties. Identification of properties is also crucial in modeling process and numerical analyses (Joszko et al., 2018, Jurkojć et al., 2017, Kusz et al., 2008).

In this paper it was attempted to determine the hysteresis of fatigue strength and also the charts of dynamic elastic modulus of swine tendons used for xenogeneic applications in reconstructive medicine.

\section{Material and methods}

All samples for testing were taken from pigs about 6 months old and weight from 80 to $100 \mathrm{~kg}$. Tests were carried out up to 24 hours after slaughter. Until the examination, the samples were stored in physiological saline at $4{ }^{\circ} \mathrm{C}$, to maintain a constant level of hydration. It was tested 50 specimens of swine tendons (10 tendons of extensor digiti II, 10 medial tendons of digiti III, 10 anterior tendons of digiti III

Kamil Joszko, PhD., Eng.: Department of Biomechatronics, Faculty of Biomedical Engineering, Silesian University of Technology, Zabrze, PL, kjoszko@polsl.pl

** Bożena Gzik-Zroska, PhD., Eng.: Department of Biomaterials and Medical Devices Engineering, Faculty of Biomedical Engineering, Silesian University of Technology, Zabrze, PL, bgzikzroska@polsl.p1

*** Full prof. Marek Gzik: Department of Biomechatronics, Faculty of Biomedical Engineering, Silesian University of Technology, Zabrze, PL, mgzik@polsl.pl

$\dagger$ Edyta Kawlewska, PhD. Eng.: Department of Biomechatronics, Faculty of Biomedical Engineering, Silesian University of Technology, Zabrze, PL, ekawlewska@polsl.pl

$\$ \quad$ Michał Burkacki, MSc. Eng.: Department of Biomechatronics, Faculty of Biomedical Engineering, Silesian University of Technology, Zabrze, PL, michal.burkacki@polsl.pl

\# Sławomir Suchoń, MSc. Eng.: Department of Biomechatronics, Faculty of Biomedical Engineering, Silesian University of Technology, Zabrze, PL, slawomir.suchon@polsl.pl 
and IV, 10 tendons of extensor digiti IV, 10 tendons of extensor digiti V). It was carried out 30 static and 30 dynamic probes. Before the test all specimens were measured to calculate cross section area, which necessary to determine stresses.

Static tensile tests were carried out on the MTS Insight 2 machine - a strength testing machine for static testing of stretching, compression and bending with computerized measurement registration of force (up to $2 \mathrm{kN}$ ) and elongation. In the laboratory it was provided the constant temperature $21^{\circ} \mathrm{C}$. At first the prepared specimens were fixed in specially designed clamps, that aimed at preventing spontaneous slipping of samples from the holders, as well as eliminating the phenomenon of stress concentration at the place of fixing the sample. Before the test it was measured the initial distance between clamps and the thickness and width of the samples. Subsequently it was perform the tensile test in the direction of the longitudinal axis of the sample in quasi-static conditions, with the velocity of $5 \mathrm{~mm} / \mathrm{min}$ (Fig. 1). The data were registered at a frequency of $10 \mathrm{~Hz}$. If the rupture occurred closer than $20 \mathrm{~mm}$ to the clamps, the probes were excluded.

Dynamic tests were performed with the use of MTS Bionix machine (at a frequency of $2 \mathrm{~Hz}$ ), that makes it possible to conduct repeatable tests of fatigue life, fracture mechanics, tension, bending and compression at the range of axial force $0-25 \mathrm{kN}$. One test duration was about 42 minutes. Sensors used in static and dynamic tests provide the first class of accuracy, so it was assumed the linearity even in bottom load ranges.

\section{Results}

On the basis of the data obtained in static test it was determined the maximal failure force $\mathrm{F}_{\max }[\mathrm{N}]$. It was calculated average values with standard deviations for each groups of specimens (tendons of extensor digiti II: $238.26 \pm 10.9$ [N], medial tendons of digiti III: $204.49 \pm 7.9$ [N], anterior tendons of digiti III and IV: $263.85 \pm 15.3[\mathrm{~N}]$, tendons of extensor digiti IV: $264.89 \pm 18.9[\mathrm{~N}]$, tendons of extensor digiti V: $138.67 \pm 10.2[\mathrm{~N}])$. These results were also used to determine the conditions for fatigue test, in which each specimen was subjected to a load equals $75 \%$ of the maximum force determined from a static tensile test.

The course of the given load was sinusoidal in the range from $25 \%$ to $75 \%$ of the maximum load. During tests it was registered the sample load value in relation to the actuator displacement. On the basis of obtained data it was calculated stress and strains. As part of the fatigue tests, hysteresis loops for fatigue strength and charts of the dynamic elastic modulus were determined.

a)

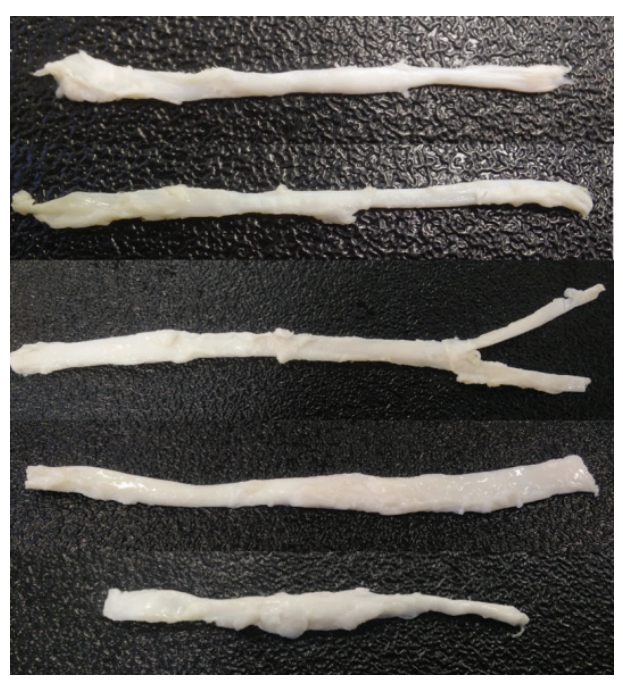

b)

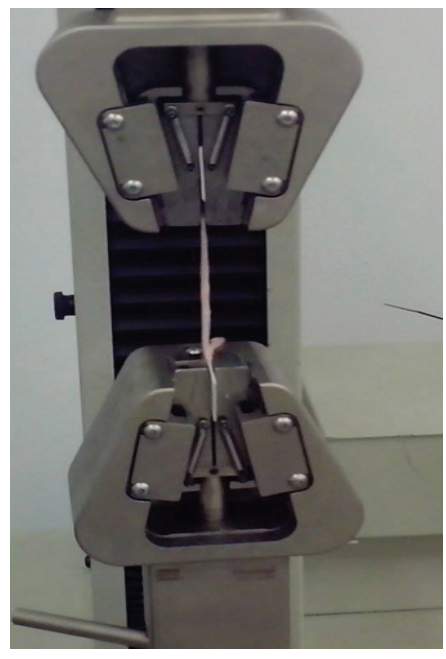

Fig. 1: a) prepared specimens of tendons, b) specimen fixed in the machine

During the investigations it was observed the phenomenon of cyclic creep of the tested material that was shown by the displacement of hysteresis loop (increasing strains) with decreasing angle of inclination in subsequent cycles (Fig. 2). This phenomenon is strictly connected with changing dynamic modulus of elasticity. The values of the dynamic modulus of elasticity was determined on the basis of the incisions, 
carried out by the hysteresis loops. The change of the dynamic elastic modulus which took place in subsequent cycles $n$ for all tendons types were presented in the Fig. 3.

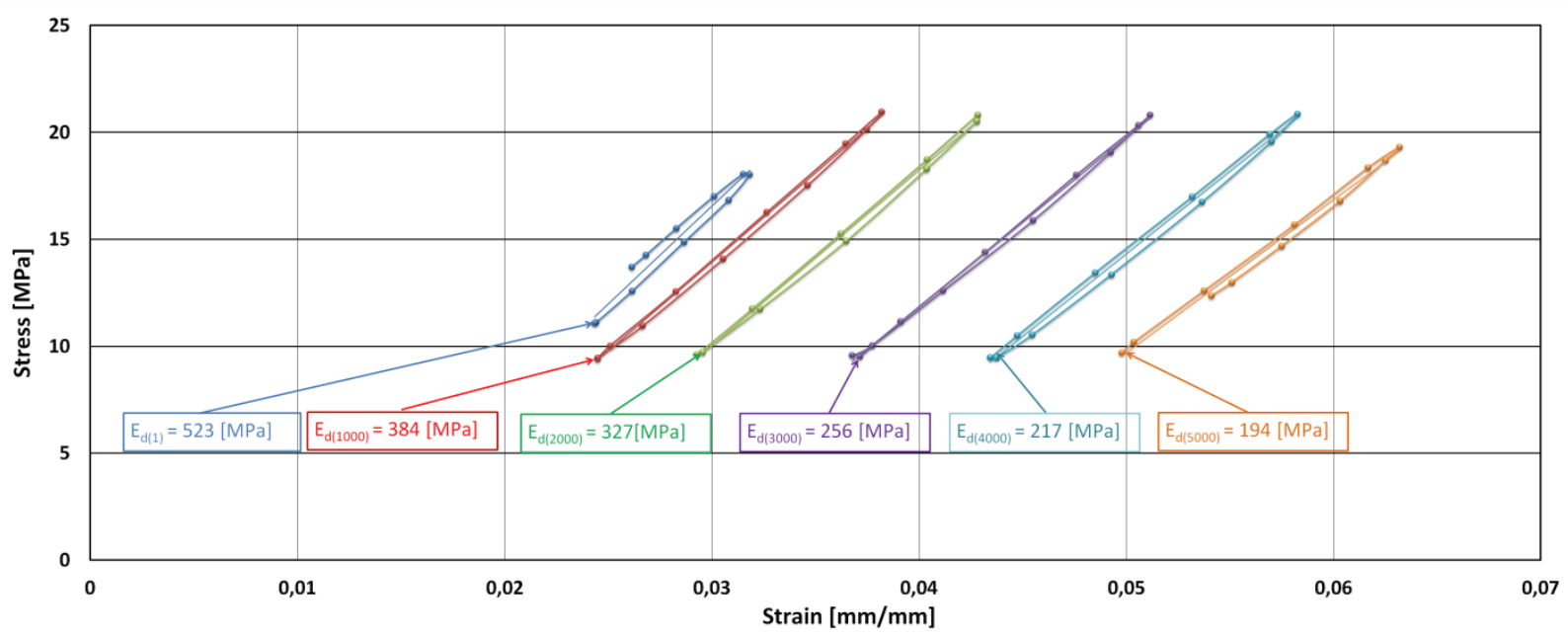

Fig. 2: Exemplary hysteresis after different number of cycles registered during fatigue tests of anterior tendons of digiti III and IV

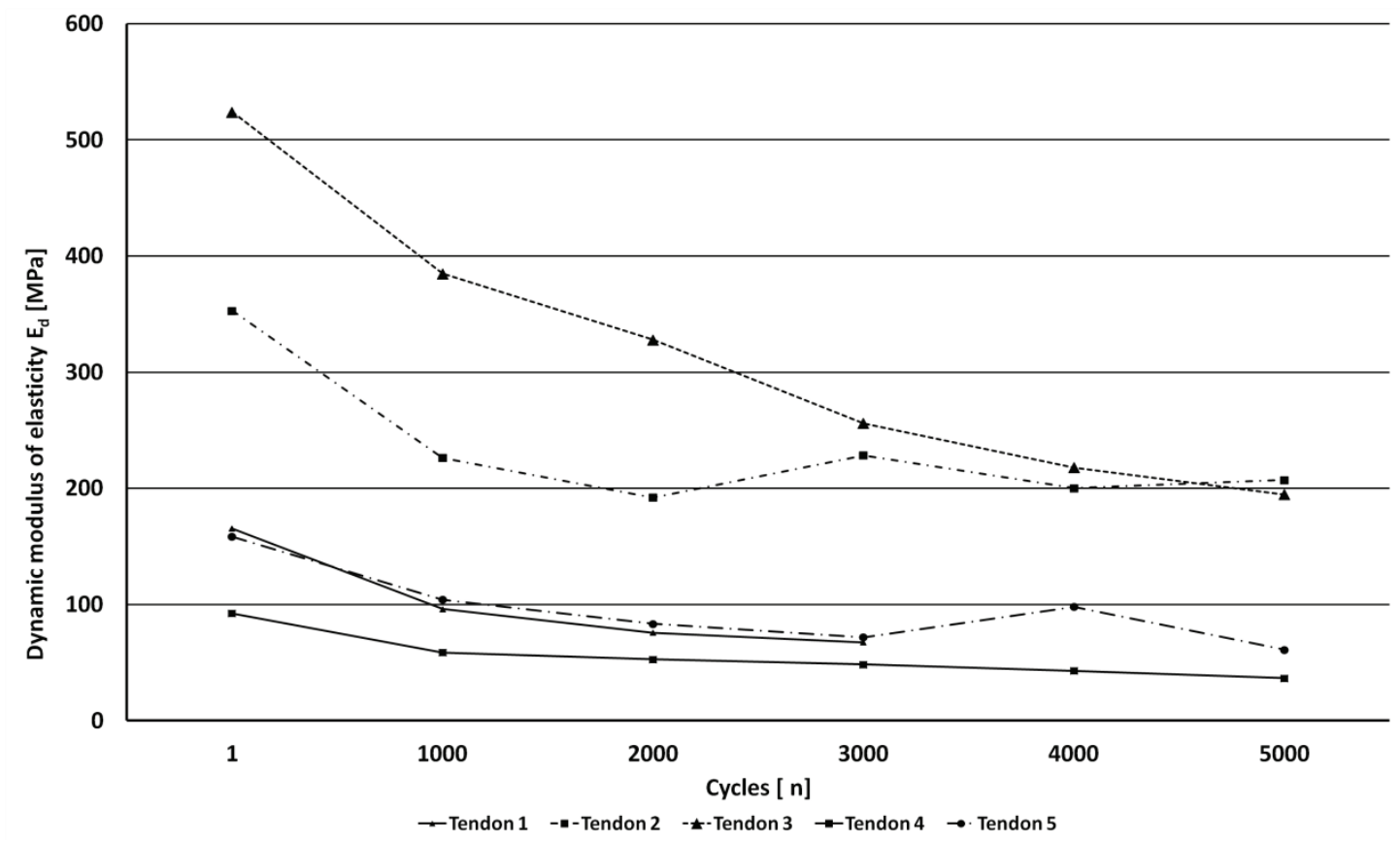

Fig. 3: Changes of dynamic module of elasticity Ed in subsequent cycles $n$ (1 - tendon of extensor digiti II,2 - medial tendon of digiti III, 3 - anterior tendon of digiti III and IV, 4 - tendon of extensor digiti $I V, 5$ - tendon of extensor digiti $V$ )

The highest dynamic modulus of elasticity $E_{d}$ was calculated for the anterior tendons of digiti III and IV. This is the basis for concluding that this type of tendon is characterized by the least cyclical creep.

\section{Conclusions}

In this paper it was conducted the experimental tests of swine tendons under dynamic loads conditions. It was stated that the low-cycle fatigue test is an appropriate method to evaluate the biomechanical properties of tendons durability, due to the similar conditions that occur during human movement. From the medical point of view, the use of xenogeneous material with the highest durability is expected in order to ensure the long-term functioning of the transplanted structure in which xenotransplantation has been used. The anterior tendon of digiti III and IV in comparison to other tendon types, retains its viscoelastic properties to a greater extent. 
Evaluating the biomechanical properties of swine tendons it could be state that in xenogeneic transplants (i.e. for patella tendon) the use of anterior tendon of digiti III and IV seems to be the most optimal.

\section{References}

Joszko, K., Gzik, M., Wolański, W., Gzik-Zroska, B. and Kawlewska, E. (2018) Biomechanical evaluation of human lumbar spine in spondylolisthesis. Journal of Applied Biomedicine, 16, 1, pp. 51-58.

Jurkojć, J., Wodarski, P., Michnik, R., Nowakowska, K., Bieniek, A. and Gzik, M. (2017) The upper limb motion deviation index: a new comprehensive index of upper limb motion pathology. Acta of Bioengineering and Biomechanics, 19, 2, pp. 175-185.

Kajzer, A., Kajzer, W., Gzik-Zroska. B., Wolański, W., Janicka. I. and Dzielicki, J. (2013) Experimental biomechanical assessment of plate stabilizers for treatment of pectus excavatum. Acta of Bioengineering and Biomechanics, 15, 3, pp. 113-21.

Kemper, A., McNally, C., Pullins, C., Freeman, L. and Duma, S. (2007) The biomechanics of human ribs: material and structural properties from dynamic tension and bending tests. Stapp Car Crash Journal, 51, pp. 235-73.

Kusz, D., Wojciechowski, P., Cieliński, Ł., Iwaniak. A., Jurkojć, J. and Gąsiorek, D. (2008) Stress distribution around a TKR implant: are lab results consistent with observational studies? Acta of Bioengineering and Biomechanics, 10, 4, pp. 21-26.

Perz, R., Toczyski, J. and Subit, D. (2015) Variation in the human ribs geometrical properties and mechanical response based on X-ray computed tomography images resolution. Journal of The Mechanical Behavior of Biomedical Materials, 41, pp. 292-301.

Pezowicz, C. and Głowacki, M. (2012) The mechanical properties of human ribs in young adult. Acta of Bioengineering and Biomechanics, 2, 14, pp. 53-60.

Szarek, A., Korytkowski, M., Rutkowski, L., Scherer, R. and Szyprowski, J. (2012) Forecasting wear of head and acetabulum in hip joint implant. In: Rutkowski L., Korytkowski M., Scherer R., Tadeusiewicz R., Zadeh L.A. and Zurada J.M. (eds) Artificial Intelligence and Soft Computing. ICAISC 2012. Lecture Notes in Computer Science, vol 7268. Springer, Berlin, Heidelberg. 